EL DERECHO DE ENMIENDA COMO INSTRUMENTO DE INTEGRACIÓN DEL PLURALISMO POLÍTICO EN LA FASE CENTRAL DE LOS PROCEDIMIENTOS LEGISLATIVOS DE LAS CORTES GENERALES

ANA MARIAA REDONDO GARCÍA 


\section{SUMARIO}

1. Introducción. 2. Algunos problemas en cuanto a la naturaleza juRidica de LA ENMIENDA. 3. Límites AL CONTENIDO dE LA ENMIENDA. 4. LAS RESTRICCIONES QUE incorpora el artículo 134.6 de LA Constitución. 5. El DERECHO de ENMienda COMO MANIFESTACIÓN DE LOS DERECHOS EN LA REPRESENTACIÓN DEL ARTÍCULO 23 DE LA CONSTITUCIÓN. 


\title{
EL DERECHO DE ENMIENDA COMO INSTRUMENTO DE INTEGRACIÓN DEL PLURALISMO POLÍTICO EN LA FASE CENTRAL DE LOS PROCEDIMIENTOS LEGISLATIVOS DE LAS CORTES GENERALES
}

\author{
POR \\ ANA MARÍA REDONDO GARCÍA
}

\section{INTRODUCCIÓN}

El Parlamento, como su nombre indica, es un órgano en el que se parlamenta, en el que se delibera. El debate como método para la toma de decisiones es la seña de identidad de los procedimientos de formación de la ley y, aunque su fisonomía y sus características hayan evolucionado en el transcurso de la historia, el Parlamento continúa siendo, en esencia, un órgano representativo deliberante.

Estas dos notas, la representatividad de la Asamblea y su carácter dialéctico y contradictorio, se proyectan en el procedimiento legislativo, siendo la enmienda un instrumento útil para la representación de intereses y para la concreción del debate.

En la evolución sufrida por el Parlamento desde los albores del Estado liberal hasta nuestros dias se hallan las claves para analizar tanto el instrumento parlamentario que la enmienda es, como el derecho de enmienda integrante del status constitucional del parlamentario. 
No puede soslayarse que esta institución ha sufrido un cambio de significado en el tránsito del Parlamento liberal al Parlamento democrático.

Como se sabe, las Asambleas liberales eran órganos deliberantes, en busca de una verdad racional que coincidía básicamente con los intereses pretendidamente unívocos de la burguesía, mientras que el Parlamento democrático es una Asamblea igualmente deliberante en la que si bien las decisiones deben ser adoptadas siguiendo el criterio de la mayoría, las minorías tienen un derecho de representación y un derecho a ser oídas en el legislativo sin que puedan ser excluidas de la creación del orden jurídico'.

Pues bien, la característica común a ambos modelos de Parlamento es el hecho de que, previamente a la adopción del texto definitivo, se delibera sobre su contenido con publicidad. Mas a partir de esta esencia común que se corresponde con la naturaleza misma del Parlamento, las diferencias son notables, no tanto en el esquema procedimental que las Asambleas siguen para formar su voluntad, como en el significado y la función del debate y el resultado del mismo, esto es, la ley, que en absoluto es un concepto estático que signifique lo mismo en los albores del siglo XIX que en las postrimerías del XX.

Es preciso indicar que dicha evolución del Estado ha llevado aparejados profundos cambios en la estructura y funciones del Parlamento que, rara vez, se han visto reflejados en una adecuación consecuente de los procedimientos legislativos, cuya estructura apenas ha variado en cerca de dos siglos.

Es un hecho que la democratización del Parlamento y del Gobierno, la evolución del concepto de representación, la irrupción de los grupos parlamentarios como auténticos protagonistas de la actividad de la

1 En efecto, las Asambleas estamentales tienen, como una de sus funciones primordiales la de aconsejar al Rey y defender los intereses nobiliarios del Reino, negociando las exigencias - casi siempre tributarias- del monarca, en ocasiones excesivas. El Parlamento liberal burgués, al que se atribuye, según la fórmula de la división de poderes, la función de hacer la ley, se sirve del procedimiento contradictorio de opiniones para alcanzar la "razón legal», mientras en el Parlamento democrático la decisión la tiene la mayoría que sustenta al Gobierno, pero los grupos minoritarios tienen el deber político y el derecho a exponer sus posiciones y a ser escuchados públicamente. Cfr. Acerca de este proceso de transformación, A. Garrorena Morales, Representación política y constitución democrática (hacia una revisión crítica de la teoría de la representación), Madrid, Cívitas 1991; La obra colectiva, El Parlamento y sus transformaciones actuales, Madrid, Tecnos 1990; 
Cámara, el reconocimiento constitucional de derechos a las minorías o la nueva relación entre Ejecutivo y Legislativo son, entre otros, elementos que han producido mutaciones sustanciales en la naturaleza de los instrumentos parlamentarios.

A lo largo de la investigación he podido constatar que la facultad de presentar enmiendas ha sufrido transformaciones en relación con las funciones que cumple $y$ a la finalidad que pretende.

Hay que recordar, en primer lugar, que los parlamentarios liberales articulaban el debate en torno a la capacidad disuasoria y a la idea de que es posible el convencimiento mutuo en aras de alcanzar una ley racional y equilibrada.

Los intereses de la sociedad liberal burguesa al entenderse homogéneos se presumían más fácilmente conciliables. Consecuentemente con este espíritu, las propuestas alternativas de los representantes se debatían fundamentalmente en el Pleno de la Cámara, sin apenas limitaciones en la utilización de la palabra y con reiteraciones en los turnos de intervención, siendo el Pleno el órgano que tomaba la decisión sobre las propuestas que convenía introducir en el texto.

De este modo, las enmiendas se consideraban un elemento fundamental para configurar el contenido de la legislación.

En segundo lugar, a través de enmiendas se pretendía mejorar la calidad técnica de la ley, corrigiendo aquellos errores de expresión o de sistemática que afectaban al buen entendimiento de la norma.

Este tipo de enmiendas eran las más frecuentes, si bien, en algunas ocasiones, su incidencia rebasaba la esfera puramente gramatical, repercutiendo en el espiritu y significado de la ley.

Por último, la facultad de presentar estas propuestas sirvió episódicamente para ralentizar el trabajo de la Asamblea, debido a su potencial obstruccionista y a la flexibilidad con la que se desarrollaban los discursos parlamentarios. Efectivamente, la disponibilidad de tiempo que tenía el representante para exponer sus puntos de vista favorecia el abuso en el empleo de la palabra y, de hecho, estas prácticas filibusteras fueron una de las principales causas por las que se introdujeron en los Reglamentos parlamentarios importantes restricciones a la facultad de proponer y defender enmiendas.

Pues bien, si la enmienda conserva estas funciones y continúa siendo un instrumento indispensable para la fijación del debate, un mecanismo al servicio de la técnica legislativa e incluso, a veces, un arma obstruccionista, lo cierto es que la superación del modelo liberal 
ha propiciado un cambio de orientación de los procedimientos legislativos. De este modo, en los modernos sistemas parlamentarios la dialéctica mayoría-Gobierno (por un lado)/minorías-oposición (por otro) se traduce en un cuasi monopolio de la función legislativa por parte del primer binomio. El Ejecutivo es el principal impulsor de la legislación y la mayoría que le sustenta es la encargada de respaldar sus iniciativas y sacarlas adelante.

En este sentido es preciso reconocer que, en la actualidad, el Parlamento no es únicamente un órgano legislativo sino que cumple primordialmente otros cometidos a los que sirven también instrumentos como la enmienda.

Estas funciones son, por un lado, la de legitimar el sistema politico y representar los intereses concurrentes en una sociedad plural, posibilitando, de este modo la alternancia de distintas opciones en el poder y por otro, la de controlar y fiscalizar la actividad del Ejecutivo.

En relación con la primera función apuntada, el Parlamento es la única institución en la que están presentes todos los intereses relevantes de una colectividad heterogénea.

Como órgano, el Parlamento elabora la ley y es la mayoría quien decide el contenido de la norma, pero como institución, en la Asamblea se hace posible la participación de múltiples opciones que defienden sus enmiendas en el transcurso del procedimiento parlamentario ${ }^{2-3}$. De ahí que instrumentos como éste, propios de la función legislativa cobren hoy un significado más amplio y sirvan para hacer presente, en sede parlamentaria, el pluralismo político.

En relación con el control de la política gubernamental, como ya afirmara a mediados del siglo XIX J.S. MiLL, el control es la finalidad propia y sustancial de las Cámaras legislativas. La labor de fiscalización consiste en vigilar y evidenciar públicamente los incumplimientos del Ejecutivo, y es a este objetivo al que, en mayor o menor grado, sirven la generalidad de los instrumentos parlamentarios.

Desde esta perspectiva puede entenderse el control político en un sentido amplio, no solamente como aquél que ejerce el Parlamento

2 En palabras de H. KELSEN, "excluir a una minoria de la creación del orden juídico sería contrario al principio democrático y al principio mayoritario, aun cuando la exclusión fuese decidida por una mayoría", Teoría General del Derecho y del Estado, UNAM, México 1979, pág. 341.

$3 \quad$ J.S. MILL, Del Gobierno representativo, Madrid, Tecnos (Colección Clásicos del Pensamiento), 1985, págs. 64 y ss. 
sobre el Gobierno sino también el que ejerce la mayoría sobre el Ejecutivo, las minorías sobre la mayoría y claro está, la sociedad sobre sus representantes, ya pertenezcan éstos al bloque de la mayoría, ya pertenezcan a la oposición.

En este sentido la enmienda se presenta como una utilísima facultad de control ordinario ${ }^{4}$, que se puede actuar sobre el Ejecutivo por parte de la mayoría que le sostiene y, claro está, por la oposición. Control sobre el contenido de la ley y control de los representados sobre sus representantes, en cuanto éstos propongan o no alternativas coincidentes con los intereses que se comprometieron a defender.

El derecho de enmienda no es pues, un instrumento monopolizado por los grupos minoritarios, es una facultad de todos los sujetos parlamentarios, ya sean grupos o diputados. Así pues, a través de enmiendas, la mayoría puede influir en las iniciativas de otros grupos y en las del propio Ejecutivo y en definitiva, inspirar y controlar el contenido de la legislación, provenga de quien provenga.

Pero al mismo tiempo, la enmienda se revela como un mecanismo que compensa el protagonismo que, tanto la Constitución como los Reglamentos atribuyen al tándem Gobierno-mayoría en los procedimientos de formación de la ley.

$Y$ es que, si se reconoce que, en un modelo de parlamentarismo racionalizado, la conversión en ley de las proposiciones de los grupos minoritarios, no es asunto sencillo, se advertirá que la vía de participación más eficaz que tienen estos representantes es la enmienda y, en este sentido se manifiesta como un instrumento idóneo tanto para propiciar una participación plural en la conformación del ordenamiento, como para hacer oposición.

\section{ALGUNAS CUESTIONES EN TORNO A LA NATURALEZA JURÍDICA DE LA ENMIENDA}

El estudio de las sucesivas normas constitucionales y reglamentarias, junto con la observación de la práctica, permite comprender mejor el alcance de este instrumento y diferenciarlo de la iniciativa, (la

$4 \quad$ Acerca de la multifuncionalidad de los instrumentos parlamentarios y concretamente del procedimiento legislativo como vehículo de control, vid. M. ${ }^{a}$ A. Garcia Martinez, La actividad legislativa del Parlamento como mecanismo de control político", en R.C.G., n. $14,1988$. 
hermana mayor), institución con la que a menudo se ha equiparado e incluso confundido la enmienda.

En efecto, con frecuencia, en los manuales y monografías sobre derecho parlamentario a penas se advierten diferencias sustanciales entre iniciativa legislativa y enmienda, definiéndose esta última como una iniciativa menor, una pseudopropuesta o simplemente como el corolario de la iniciativa. Sin embargo entendemos que estos dos instrumentos son esencialmente distintos y sus diferencias radican no sólo en relación con los sujetos legitimados para actuarlos, o en cuanto al momento procedimental en el que se accionan, sino sobre todo, en las finalidades a las que responden uno y otro vehículo de participación.

Para defender esta distinta naturaleza es necesario ahondar en los orígenes de ambas instituciones que, en absoluto coinciden en el tiempo.

El tópico de que la facultad de proponer alternativas y modificaciones a los textos de iniciativa es consustancial a la discusión parlamentaria se desmorona ante la observación detallada de normas y usos parlamentarios.

Obviando la explicación de fondo, esto es, que los Parlamentos en donde no se admite el derecho de enmienda, a duras penas pueden considerarse Asambleas representativas y menos aún democráticas, lo cierto es que, por primera vez en nuestra historia parlamentaria, se introduce el concepto enmienda en el Reglamento del Congreso de $1838^{5}$.

5 Por primera vez en una norma parlamentaria se utiliza el término «enmienda", en el artículo 98, con el significado de modificación, en sede parlamentaria, del texto de iniciativa. En efecto, la práctica parlamentaria anterior en relación con los debates, consistía en discutir el proyecto que finalmente se sometía a votación para la aprobación o rechazo del texto integro, sin que, de ordinario se introdujeran más modificaciones que las estrictamente formales. El hecho de que los procuradores pudiesen introducir modificaciones parciales y adiciones al texto, enriqueció notablemente las funciones de los parlamentarios y permitió una mayor participación de las minorías en la elaboración de la ley. El derecho de enmienda se reguló de manera muy flexible sin que se establecieran, apenas, limitaciones a su ejercicio. El enmendante tenía derecho a defender su propuesta ante la Comisión que, a través de uno de sus miembros, respondía a aquella intervención admitiendo o desechando la enmienda. Los asuntos complejos debían superar un doble debate: una primera lectura general sobre el "principio, espíritu y oportunidad" del texto, en cuyo desarrollo se examinaban, al mismo tiempo, las enmiendas $y$ adiciones presentadas en tal sentido (art. 102) -esta primera toma de contacto con el 
Con anterioridad, pero también frecuentemente en momentos históricos posteriores, los diputados se limitaban a discutir $y$ votar las iniciativas del monarca pero no tenían reconocido el derecho de modificar los textos. Asimismo y como un ejemplo más que refuerza esta idea, el artículo 34 de la Constitución francesa de 1799, niega a los parlamentarios toda capacidad de discusión y enmienda, consistiendo su colaboración en la producción legislativa en votar el proyecto tal y como era depositado en la Cámara.

Históricamente, tampoco coinciden los requisitos de legitimación para presentar iniciativas y enmiendas. El estudio de la normativa pretérita desvela una sutil pero importante diferencia.

Los Reglamentos exigían que los titulares del escrito de enmiendas fueran al menos siete parlamentarios, mientras que los firmantes de la iniciativa debían de ser como máximo siete.

La razón de semejante regulación la explicó, en su día, el entonces diputado en Cortes Sr. Pacheco, del siguiente modo: "Cuando un número considerable de parlamentarios firma una proposición de ley es porque o bien ha habido previa discusión sobre el asunto o no la ha habido. En el primer caso ha sido fuera de las Cortes, donde no debe ser; y si no ha precedido discusión, al firmar la proposición ha habido compromisos, deferencias... es necesario que la discusión tenga la mayor latitud y que sea lo más libre posible, mientras que la razón de que se exija que la enmienda se presente respaldada por un mayor número de firmas reside en el hecho de que son textos en muchas oca-

texto del proyecto equivalía a un debate de totalidad muy similar al que se recoge dentro del procedimiento legislativo ordinario en los actuales reglamentos-, y una segunda lectura más técnica llevada a cabo por la Comisión encargada de elaborar el dictamen. El título VIII del Reglamento del Congreso de 1938 recogía el modelo francés de secciones y comisiones como fórmula de racionalizar y distribuir el trabajo legislativo. Cada Comisión era nombrada al efecto para el conocimiento de una determinada materia y desaparecía cuando el proyecto era votado, tal y como se hacia en el país vecino. Cfr. M.M.- Fralle Clivillés, La Comisión permantente de las Cortes, Editora Nacional, Madrid 1974, págs. 18 y ss. Únicamente, en los artículos 85 a 91 se preveían seis comisiones permanentes, a saber: la Comisión de actas electorales, la de presupuestos, la de examen de cuentas, la de peticiones, la de gobierno interno y la de corrección de estilo; la importante labor de estas comisiones y la mayor complejidad que implicaba la configuración de las comisiones no permanentes, provocaría con el tiempo la consolidación del modelo de comisiones permanentes, de modo similar a como evolucionaría el sistema francés a a partir de 1848. Vid., L. VILLACORTA MANCEBO, Hacia el equilibrio de poderes. Comisiones legislativas y robustecimiento de las Cortes, Publicado por la Universidad de Valladolid, 1989, págs. 117. 
siones presentados de forma masiva con interés obstruccionista, de tal modo que es conveniente imponer más requisitos, con el objeto de limitar el potencial abuson".

Pero además, iniciativa y enmienda se diferencian en cuanto a los fines que persiguen uno y otro instrumento parlamentario.

Así, mientras la iniciativa es uno de los principales motores con los que cuenta el Ejecutivo para impulsar su política y sacar adelante sus compromisos electorales, la capacidad de presentar enmiendas resulta ser un elemento que equilibra el protagonismo del Ejecutivo en la elaboración de la ley, permitiendo a los sujetos parlamentarios ejercer la función legislativa que constitucionalmente les corresponde.

En efecto, a través de enmiendas los representantes colaboran en la formación de la ley y al mismo tiempo dan a conocer sus propuestas y alternativas. Todo ello sin olvidar que también, a través de enmiendas, la mayoría puede controlar y modificar las iniciativas que se someten a discusión.

Por último, la naturaleza jurídica de ambas instituciones se diferencia por cuanto la enmienda es siempre una propuesta subsidiaria y referida al texto que se discute como principal. Efectivamente, la enmienda es un texto materialmente ligado y subordinado al del proyecto. Esta característica es precisamente lo que define la enmienda; lo que constituye su esencia.

De este modo, el sujeto que toma la iniciativa selecciona el ámbito de realidad a regular, establece el objeto y sus límites, decide el momento más oportuno para que se debata la propuesta, y fija los principios y fundamentos de la misma en un texto que debe ser razonable y coherente. Por el contrario, quien formula enmiendas está limitado por cuanto ha de presentar una alternativa congruente con la materia y el contenido que es objeto del proyecto.

En este punto es preciso traer a colación la evolución producida en la Jurisprudencia del Tribunal Constitucional desde una concepción formal de enmienda hasta otra material.

En la primera decisión sobre este asunto, la Sentencia 99/1987, de 11 de junio ${ }^{7}$, el Tribunal manifiesta que no existe ni en la Constitu-

$6 \quad$ D.S.C. de 27 de noviembre de 1837, págs. 276-78.

7 El Recurso de inconstitucionalidad lo promueven 53 diputados contra determinados preceptos de la Ley 30/1984, de 2 de agosto, de Medidas para la Reforma de la Función Pública. El motivo central que argumentan los recurrentes es 
ción ni en los Reglamentos de ambas Cámaras norma alguna que establezca una delimitación material entre enmienda y proposición de ley y por lo tanto que «ni por su objeto ni por su contenido existe limite alguno a la facultad de presentar enmiendas por parte de los Grupos parlamentarios".

Sobre la base de esta interpretación resuelve el Tribunal un Recurso de inconstitucionalidad cuyo primer motivo consiste en la impugnación parcial de la ley por vicios en el procedimiento de elaboración. Los recurrentes entendían que se había producido una grave distorsión en el método de producción legislativa al introducirse, vía enmienda, nuevas disposiciones adicionales, con la consiguiente vulneración de los artículos 87.1, 89 y 90 de la Constitución.

De la Sentencia se extrae una regla que consiste en considerar que cualquier texto puede tramitarse como enmienda, siempre que se presente como tal y cumpla los requisitos que el ordenamiento jurídico impone. En definitiva, esta primera línea jurisprudencial consagra un concepto formal de enmienda que permite la introducción de contenidos de todo tipo en el texto del proyecto, cuando así lo decida la mayoría.

La segunda vez que el Tribunal se pronuncia en concreto sobre la naturaleza jurídica de la enmienda es en la Sentencia 23/1990, de 15 de febrero ${ }^{8}$.

En aquella ocasión los Diputados del CDS en las Cortes Valencianas interpusieron Recurso de Amparo frente a una Resolución de la Mesa que inadmitía a trámite una enmienda de totalidad de texto alternativo presentada por este grupo al proyecto de reforma del artículo 12.2 del Estatuto de Autonomía de la Comunidad Valenciana.

El contenido de dicha enmienda no sólo hacía referencia al citado artículo sino que incluía propuestas alternativas para otros ocho

la inconstitucionalidad formal por vicios en el procedimiento de elaboración de la ley. Afirman los recurrentes que se ha producido una grave distorsión en el método de producción legislativoa al incluirse, vía enmienda, en la ley una serie de disposiciones adicionales con la consiguiente vulneración de los artículos $87.1,89$ y $90 \mathrm{CE}$, en relación a los artículos 123 y $125 \mathrm{RCD}$ y $108 \mathrm{RS}$. En el fundamento jurídico primero de la Sentencia el Tribunal manifiesta que los recurrentes no apoyan sobre base normativa alguna su reclamación y aunque el artículo 28.1 de la LOTC menciona los Reglamentos parlamentarios entre aquellas normas cuya infracción puede acarrear la inconstitucionalidad de la Ley, no existe disposición reglamentaria que establezca una delimitación material entre enmienda y proposición de ley y tampoco se deduce esta exigencia del propio Texto Constitucional. BJC, n. ${ }^{974}$, págs. 728-29.

$8 \quad B J C$, n.ำ107, págs. 74 y ss. 
preceptos del Estatuto. Al igual que en decisiones posteriores, me refiero a los Autos 275/1993, y 118/1999 de 10 de mayo, el Tribunal opta aquí por un concepto material de enmienda, haciendo derivar de la propia naturaleza del texto alternativo el requisito de conexión material y congruencia necesaria del contenido de la enmienda en relación con el de la iniciativa.

Como ya he señalado esta última línea jurisprudencial me parece la acertada y constitucionalmente adecuada, puesto que el hecho de seguir una concepción material de enmienda evita distorsiones en el procedimiento legislativo derivadas, por ejemplo, de que se eliminen los requisitos estrictos que el Reglamento exige para la presentación de iniciativas o de que se lesionen los principios democrático y pluralista a lo largo del procedimiento.

Pero es que además, la exigencia de congruencia y conexión material impone una correcta técnica legislativa lo que repercute en una mayor calidad de las leyes, facilita su entendimiento y aplicación y en definitiva, aumenta el grado de seguridad jurídica.

La conclusión a la que se llega tras analizar el derecho positivo y la jurisprudencia constitucional al respecto, es que lo relevante, lo que diferencia el texto de la iniciativa del escrito de enmiendas no son los requisitos formales ni temporales o de legitimación que imponen los reglamentos, sino el carácter subsidiario del contenido de la enmienda con respecto de aquél que constituye el proyecto. Es decir, la propia naturaleza de la enmienda consiste en ser un documento accesorio, necesariamente congruente con respecto del de iniciativa, con el que debe guardar siempre relación de subordinación ${ }^{10}$.

La consecuencia inmediata de esta tesis es que el escrito de enmiendas no puede incorporar contenidos novedosos sin vínculo directo con aquéllos que el titular de la propuesta principal ha decidido libremente incorporar a la misma.

Llevando el argumento a sus últimas consecuencias, se llega a la conclusión de que una enmienda a la totalidad, alternativa al proyecto

$9 \quad$ Por su claridad traemos a colación un párrafo incluido en el FJ $4 .^{9}$ del ATC 118/1999 de 10 de mayo: "Se requiere una correlación material entre la enmienda $y$ el texto enmendado como condición de procedibilidad que es inherente al carácter subsidiario o incidental por su propia naturaleza, de toda enmienda respecto del texto enmendadon.

${ }_{10}$ Con respecto a la conveniencia de configurar un concepto material de enmienda léase, por todos, el trabajo de A. ARCE JANARIZ, "El derecho de enmienda visto por el Tribunal Constitucional», REDC, n. 41, mayo-agosto 1994. 
del Gobierno no podrá convertirse en ley, si el Ejecutivo decide retirar su proyecto con anterioridad a su aprobación final. Tal consecuencia deriva de la interpretación, entiendo que adecuada, de los artículos 112.5 y 128 del RCD. Es decir, el Parlamento no puede imponer una determinada legislación al Ejecutivo $\gamma$ en este sentido, una enmienda a la totalidad alternativa no podrá suplantar al proyecto de ley si el Ejecutivo decide la retirada de su texto ${ }^{11}$.

1 El artículo 128 RCD ordena: «El Gobierno podrá retirar un proyecto de ley en cualquier momento de su tramitación ante la Cámara, siempre que no hubiere recaido acuerdo final de ésta." En similares términos el artículo 127 del RS establece que "Los proyectos de ley presentados por el Gobierno pueden ser retirados por éste en todas las fases del procedimiento anteriores a su aprobación definitiva por la Cámara». Se trata pues de resolver qué se entiende por acuerdo final sobre el texto del proyecto o por aprobación definitiva. En este punto dos son las respuestas posibles: en primer término, cabe entender que cuando la Cámara vota a favor de la enmienda de texto alternativo ha decido definitivamente sustituir el texto primigenio por el de la enmienda, por tanto ha adoptado un acuerdo final en relación con el proyecto $y$, en consecuencia, la retirada del texto del Gobierno únicamente se podría producir en este momento inicial del procedimiento previo a la aprobación del texto alternativo. Parece poco probable que el Ejecutivo decida retírar un proyecto meditado y sopesado días despues de su presentación, sin saber cual puede ser el apoyo parlamentario con el que puede llegar a contar. Esta interpretación restrictiva en cuanto al momento de retirada del texto gubernamental no se adecua muy bien al modelo de parlamentarismo racionalizado que disaña nuestro ordenamiento jurídico y que da prioridad a la acción del ejecutivo como impulsor $y$ orientador del procedimiento legislativo. Por otro lado, una interpretación literal del término "aprobación final" parece excluir el hecho de que sea el momento de la sustitución del texto de la iniciativa por el de la enmienda el límite temporal a la facultad que tiene el Gobierno de retirar su proyecto. A mayor abundamiento se pueden utilizar otros dos argumentos. En primer lugar, como afirma el Profesor Aragón Reyes, "La iniciativa legis/ativa", $R E D C$, n. 16, enero-abril 1986, pág. 296: "si iniciar consiste en poder retirar" y si de este dominio sobre el texto depende el que se detente el poder de iniciativa, el hecho de afirmar que el Gobierno, por mor del artículo $87 \mathrm{CE}$, goza de dicho poder implica reconocer que es el Ejecutivo quien decide sobre la retirada de su texto, sin que, contra su voluntad pueda imponerle la Cámara un texto alternativo. Por otro lado hay que tener en cuenta que el texto del proyecto no se mantiene imperturbable a lo largo del procedimiento; puede ser modificado de forma sustancial en Comisión, y a pesar de ello, en este caso, nada impide que el Gobierno retire el proyecto originario que ha sido sustituido por otro texto, el del dictamen, sobre el que se proyectan las sucesivas fases procedimentales. Mantener la tesis de que, tras la aprobación de la enmienda de totalidad de texto alternativo, el Gobierno ya no puede ejercer la facultad de retirada, puesto que el nuevo texto no le pertenece, equivale a equiparar enmienda de totalidad e iniciativa legislativa. Sin pretender aferrarme contra toda lógica a un determinado nomen iuris, considero conveniente no obstante, mantener las categorías jurídicas mientras no existan poderosas razones que hagan recomendable su superación. Desde esta concepción entiendo que es posible defender una segunda tesis y man- 
En efecto, la iniciativa parlamentaria ha de circunscribirse a los términos en los que está regulada en los artículos 87,88 y 89 de la Constitución, y la enmienda, aunque de totalidad, no es identificable con la iniciativa legislativa. Su propia naturaleza subsidiaria y dependiente exige que su destino corra parejo al del proyecto $y$, por tanto, mientras la Cámara no tome un acuerdo final, el Gobierno puede decidir la retirada de su iniciativa con el consiguiente decaimiento de la enmienda. Ni que decir tiene que una actitud semejante del Gobierno puede tener repercusiones muy negativas de cara a los medios de comunicación y a la opinión pública, por lo que muy probablemente el Ejecutivo no esté dispuesto a correr con el coste político de una decisión de estas características, pero fuera de la esfera política, estrictamente en el ámbito jurídico, es posible mantener que un concepto material de enmienda llevado a sus últimas consecuencias impone una interpretación como la que aquí se ofrece.

Pues bien, que la iniciativa legislativa y la enmienda son instrumentos parlamentarios diferentes parece acreditarse sin dificultad a través de todos los razonamientos esgrimidos, pero la línea divisoria entre ambas figuras no resulta tan evidente. $Y$ así se pone de manifiesto a lo largo del procedimiento legislativo $y$, en concreto, de su fase central que se inicia con la apertura del plazo de presentación de enmiendas y concluye con la votación de las mismas.

Un recorrido por las normas reglamentarias vigentes y la observación de la práctica lleva a concluir que ciertamente los lindes entre iniciativa y enmienda se desdibujan con frecuencia.

Sobre este aspecto, el estudio del derecho extranjero, en especial del modelo francés, donde con más profusión se ha tratado este asunto, puede resultar de gran utilidad ${ }^{12}$.

tener el concepto enmienda para designar los textos alternativos de totalidad. Con esta predisposición puede argumenarse que, como toda enmienda, por naturaleza, la enmienda de totalidad de texto alternativo es un documento subsidiario y accidental cuya suerte corre pareja a la del proyecto. Si a esta formulación le unimos una interpretación de los artículos 127 RCD y 128 RS favorable al Ejecutivo (lo que no resulta descabellado en el contexto del parlamentarismo fuertemente racionalizado que diseña el ordenamiento jurídico español) el resultado al que se llega es que el Gobierno puede retirar su propuesta mientras la cámara no adopte un ultimo acuerdo sobre el texto de la enmienda. Una decisión del Ejecutivo en este sentido implicaria el decaimiento de la enmienda a la totalidad.

12 B. BAUFUME, ofrece en su monografía Le droit d'amendement et la constitution sous la Cinquième République, LGDJ, París 1993, un concienzudo examen del ordenamiento jurídico francés y especialmente de la práctica parlamentaria del pais vecino. 
En efecto, en el pais vecino, con frecuencia los Diputados denuncian el hecho de que determinados textos presentados como enmiendas encierran en realidad, un contenido más propio de una iniciativa distinta que de una propuesta de modificación.

Para paliar estas disfunciones que atentan contra los artículos 40 y 44 de la Constitución francesa, la Jurisprudencia del Consejo Constitucional ha ido progresivamente restringiendo la posibilidad de introducir estos cavaliers legislatifs, es decir, materias ajenas al contenido propio del proyecto, que generalmente vía enmienda se incorporan al texto legal.

En decisiones como la 76-73 de 28 de diciembre, la 94-351 de 29 de diciembre o la 97-395 de 30 de diciembre, el Tribunal francés anuló directamente varias votaciones de la Asamblea Nacional que incorporaban enmiendas de este tipo a sendos proyectos de ley ${ }^{13}$.

En nuestro país las denuncias no han sido tan abundantes pero el fenómeno en si se repite con cierta frecuencia. La aprobación e incorporación de estas enmiendas da como resultado leyes técnicamente deficientes y cuyo contenido variopinto puede poner en peligro la coherencia del texto legislativo y como consecuencia, erosionar el mismo principio constitucional de seguridad jurídica.

En este punto, es preciso reiterar la necesidad de incorporar la técnica legislativa como uno de los ingredientes del principio de seguridad jurídica.

$Y$ es que la enmienda es un instrumento parlamentario que, correctamente utilizado, puede favorecer, en gran medida, este objetivo, pero que cuando se desnaturaliza se convierte en un peligro para la coherencia del texto y en consecuencia para su conocimiento y aplicación.

Los Reglamentos de los Parlamentos próximos al nuestro contemplan estrictas reglas con el fin de cerrar el paso a propuestas incoherentes o extrañas. El ordenamiento jurídico español no introduce este tipo de preceptos que encuentran su justificación en la propia naturaleza subsidiaria de la enmienda pero que lege ferenda no estaría de más añadir para reforzar el concepto material de enmienda.

Por otro lado, el Gobierno, a través de su mayoría parlamentaria es quien más se beneficia de la utilización de esta técnica abusiva de

13 Cfr., Recueil de jurispudence constitutionnelle, coordinada por L. FavoREU, litec, Paris, 1994; Así mismo se puede consultar la jursiprudencia del Consejo Constitucional francés en la siguiente página Web: www.conseil-constitutionnel.fr/ 
los cavaliers legislatifs, porque le permite abarcar la regulación de un nuevo espectro de materias aprovechando una única iniciativa. Este modo de actuar es indudablemente ventajoso para el Ejecutivo, puesto que se consiguen introducir en la ley regulaciones que tendrían que pasar por los rigurosos trámites que para la iniciativa exigen las normas reglamentarias y, para los proyectos del Ejecutivo, la Ley 50/1997 del Gobierno.

La conclusión que en este punto del trabajo se extrae es que se hace necesario poner coto a este abuso.

Sin privar al legislador democrático de la capacidad de creación normativa que tiene reconocida constitucionalmente, es necesario, no obstante, que asuma la responsabilidad de legislar conforme a unas reglas que hagan efectivo el principio de seguridad juridica. Tal pretensión no es únicamente un desideratum o una declaración de intenciones, sino que es una exigencia constitucional que deriva directamente del apartado tercero del artículo 9 de la Norma Fundamental.

El que los Reglamentos españoles no reclamen requisitos materiales, conduce a los órganos de la Cámara que tienen encomendada la función de calificación de los escritos parlamentarios a actuar, en ocasiones, sin suficiente base normativa.

En este sentido, la Mesa de la Comisión correspondiente verificará el cumplimiento de los requisitos temporales y de legitimación, más de seguirse un concepto formal de enmienda, no podría entrar a valorar el contenido de las mismas y, en consecuencia, todo texto que se presentara como enmienda, debería ser tramitado de inmediato ${ }^{14}$.

En este punto, entiendo que si bien las Mesas o sus presidencias son órganos técnicos que no deben realizar una calificación de los escritos atendiendo a motivos políticos, no obstante si han de velar por la coherencia entre el texto de la iniciativa y el de las enmiendas.

Desde esta interpretación, los órganos de calificación sí deben controlar la congruencia de contenidos, incluso por encima de otros

14 Pese a las disfunciones que dicha práctica pueda ocasionar, esta es, no obstante, la tendencia que se sigue tanto en las Cortes Generales como en las Asambleas autonómicas y es que, los letrados encargados de informar acerca de las enmiendas suelen mostrarse favorables a que se debatan todas ellas, puesto que las decisiones en contra de su tramitación suelen ser muy impopulares y a menudo tachadas de antidemocráticas y lesivas del pluralismo politico o simplemente actuaciones que evidencian la prepotencia de la mayoria de turno, a pesar de que el rechazo a estas enmiendas esté fundamentado jurídicamente. 
requisitos de cuestionable exigibilidad como es, por ejemplo, el que los escritos de enmienda vayan rubricados por el portavoz del Grupo correspondiente.

\section{LIIMITES AL CONTENIDO DE LA ENMIENDA}

Una vez resuelta la cuestión de la naturaleza jurídica, queda por delimitar el alcance del contenido potencial de la enmienda. Para ello, se propone un breve recorrido por los límites que afectan a dicho contenido.

Concretamente las restricciones en los procedimientos de aprobación de las leyes de ratificación de tratados internacionales, los límites que impone el artículo 84 de la Constitución, aquellas exigencias derivadas de la aplicación del artículo 130.3 del Reglamento del Congreso $y$, por último, las restricciones en relación con la materia económica, cuestión ésta última que, por su trascendencia, se desarrollará con algo más de detenimiento en el epígrafe siguiente.

En cuanto a las primeras, hay que recordar, que el carácter de pacto que tienen los tratados internacionales hace que el control que sobre ellos pueden ejercer los órganos constitucionales del Estado se produzca normalmente en una fase muy tardía que desde luego no coincide con la elaboración del tratado.

Siendo esto así, sin embargo, muchos de los ordenamientos consultados exigen que la autorización para la ratificación se lleve a cabo por ley, e incluso especifican que la aprobación de esta ley deberá seguir el procedimiento ordinario ${ }^{15}$.

15 Cfr. art. 72 C.Italiana: "El procedimiento normal de examen y de aprobación directa por parte de la Cámara se adoptará...para los (proyectos de ley) de autorización para ratificar tratados internacionales"; la misma Constitución italiana en su artículo 80 repite que, "Las Cámaras autorizarán por ley la ratificación de los tratados internacionales de naturaleza política o que se refieran a arbitrajes o reglamentos judiciales o que impliquen variaciones del territorio, gravámenes en las finanzas o modificaciones de leyes.»; Art. 53 C. Francesa: "Los Tratados... no pueden ser ratificados o aprobados sino en virtud de una ley."; art. 73 Ley Fundamental de Bonn: "Corresponde a la Federación la legislación exclusiva en... 1- Los asuntos exteriores...n; En oposición a esta normativa la Constitución portuguesa en el art. 169.5 prevé que: "Revisten la forma de resolución los demás actos de la Asamblea de la República..." haciéndo referencia, entre otros al apartado j) del articulo 164 , que recoge la competencia de la Asamblea de la República para aprobar convenios internacionales. En España, dependiendo del contenido de los tratados se 
En la práctica, sin embargo, son escasas las enmiendas que se presentan a estos proyectos y ello por varias razones: en primer lugar porque se asume a priori, el protagonismo casi absoluto del Ejecutivo en estas tareas, como responsable que es de la política exterior del país; en segundo lugar, porque los Gobiernos utilizan, a veces abusivamente, fórmulas simplificadas para la conclusión de acuerdos, evitando asi el trámite parlamentario; en tercer lugar, porque el apoyo necesario que la mayoría de la Cámara brinda al Ejecutivo inhibe, en muchas ocasiones a la oposición, de presentar enmiendas de este carácter; y en cuarto y último lugar, porque cada vez es más frecuente que sean las instituciones europeas las encargadas de concluir acuerdos internacionales. Esta transferencia de competencias no redunda sin embargo en una mayor participación plural y democrática en la conclusión de los tratados, puesto que es la Comisión y no el Parlamento Europeo la que asume mayor protagonismo en el desempeño de estas funciones.

En cuanto al segundo de los límites que se ha apuntado, el artículo 84 de la Constitución otorga al Gobierno la facultad de fiscalizar el contenido de las iniciativas y enmiendas contrarias a una delegación legislativa en vigor, hasta el punto de poder vetar su tramitación mientras la ley de delegación no sea derogada expresamente ${ }^{16}$.

establecen dos fórmulas de autorización. Por un lado se autorizarán mediante ley orgánica aquellos tratados que atribuyen a una organización o institución internacional el ejercicio de competencias derivadas de la Constitución (art. 93), por otro, el resto de los tratados, señala el artículo 94.1, deberán ser autorizados previamentes por las Cámaras. No se especifica sin embargo si este acto de autorización es o no una ley. Fernando SANTAOLALLA plantea la duda: ante la falta de concrección de la Constitución, ¿habrá de entenderse la forma de ley, por analogía con el art. 93 o bien habrá que estar a la regla ubi lex voluit dixit y por tanto considerar que el acto de autorización no reviste la forma de ley? el autor demuestra en su artículo que el constituyente estaba pensando en la forma de ley para la ratificación de tratados internacionales y esgrime además razones de derecho constitucional histórico y comparado. Vid., "La Ley y la autorización de las Cortes a los Tratados internacionales", en R.D.P. de la U.N.E.D, n. ${ }^{2} 11$, otoño 1981, en especial págs. 37 y ss.

16 En el ejemplo que planteamos, aprobada una ley que en alguno de sus preceptos contradiga lo dispuesto en una ley de delegación es evidente que lo que se produce es una derogación total o parcial, en su caso, de la ley anterior con la consecuencia de que el Ejecutivo no podrá hacer uso de tal delegación si no es acatando la ley vigente. Señala J.A. Santamaria Pastor, Fundamentos de Derecho Administrativo, vol. I, C.E.U.R.A., Madrid, 1988, pág. 670, que la revocación de la delegación sólo podría llevarse a cabo, en virtud del principio de contrarius actus, mediante la aprobación de una nueva ley, por lo que no tendría eficacia jurídica, aunque sí política, la aprobación por las Cámaras de una proposición no de ley o moción en cualquier sentido opuesto a la potestad delegada. 
En mi opinión, la justificación de incluir el artículo 84 tal y como finalmente aparece redactado, bien pudiera hallarse en una reminiscencia de considerar la delegación como transferencia de potestad legislativa al Ejecutivo y no como técnica de habilitación al Gobierno para que dicte normas con eficacia semejante a la de las leyes, modelo de delegación éste último que resulta más coherente con el resto del texto constitucional y con el principio de separación de poderes que en él se articula.

Sin embargo, la Constitución no ofrece dudas: es el Gobierno el que está facultado para oponerse a la tramitación de aquellas enmiendas contrarias a una delegación en vigor.

Es incuestionable que ante un mandato tan contundente como el que se recoge en el artículo 84, los Reglamentos parlamentarios no podían haber usurpado tal facultad al Gobierno para atribuírsela a un órgano de la Cámara. No obstante, no se hubiera violentado la Norma Fundamental, con la introducción de algún mecanismo que permitiera bien a la Mesa de la Comisión, bien a la de la Cámara orientar y asesorar al Ejecutivo en una facultad que incide sobre tareas netamente parlamentarias.

En tercer lugar y en relación con las restricciones derivadas de la aplicación del artículo $\mathbf{1 3 0 . 3}$ del Reglamento del Congreso, precepto que se ocupa de aquellas enmiendas que, presentadas a un proyecto de ley ordinaria, encierran no obstante, un contenido propio de ley orgánica, es preciso indicar que el examen de la tramitación de estas normas lleva a plantear una duda razonable acerca de la limitación sobre la capacidad de enmendar que tienen los sujetos parlamentarios en el Senado y que resulta de la interpretación conjunta de los artículos 81.2 y 90.2 de la Constitución.

En efecto, si en la Cámara Alta pueden introducirse enmiendas de contenido orgánico a un proyecto de ley ordinaria y esas mismas enmiendas sólo requieren la aprobación por una mayoría simple en el Congreso, se produce una contradicción con la exigencia de mayoría absoluta en la votación final de conjunto que establece el artículo 81.2 CE.

Esta contradicción únicamente puede ser salvada entendiendo que existe para los Senadores una limitación constitucional para presentar enmiendas de contenido orgánico a proyectos y proposiciones de ley ordinaria que provengan del Congreso. Por esta razón, la solución más adecuada, en el supuesto planteado es proceder al desglose del texto en dos leyes complementarias, para que se tramiten conforme al procedimiento establecido en cada caso. 


\section{LAS RESTRICCIONES QUE INCORPORA EL ARTÍCULO 134.6 DE LA CONSTITUCIÓN}

La limitación más drástica y contundente que impone el ordenamiento jurídico español al derecho de enmienda es la reserva en materia económica.

Para aproximar una interpretación adecuada del artículo 134.6 de la Constitución se hace necesario tomar postura sobre una serie de problemas más generales referidos a la naturaleza y contenido de la propia Ley de Presupuestos.

Tras analizar la jurisprudencia constitucional y revisar las opiniones doctrinales al respecto he llegado al convencimiento de que, superada la dicotomía entre ley formal-ley material, que surge precisamente en torno a la institución presupuestaria ${ }^{17}$, la ley de presupuestos es, en nuestro ordenamiento, una ley en el único sentido en el que hoy cabe hablar de ley, esto es, un texto que sometido al procedimiento legislativo es aprobado en el Parlamento.

El constituyente gozó de libertad para configurar una pluralidad de formas legales y del mismo modo fue soberano para diseñar procedimientos legislativos diversos. En este sentido, las reglas constitucionales que configuran el procedimiento de elaboración de la Ley de Presupuestos no son una excepción, puesto que también se establecen especialidades para la producción de otras leyes.

$17 \quad$ Esta superación de las tesis que defienden la Ley de Presupuestos como una ley en sentido méramente formal, carente de contenido normativo esto es, privada de "un precepto jurídico, de una norma para regular o resolver relaciones jurídicas", (cfr., P. LABAND, El Derecho Presupuestario, IEF, Madrid 1989, pág. 8.) ha de entenderse en el concreto contexto normativo español, ya que estas teorias especialmente en Alemania, Italia y Francia, dónde tuvieron mayor predicamento, han seguido repercutiendo de una $u$ otra manera en la concepción de las categorias presupuestarias. Como afirma Alvaro Rodriguez BereiJo, la superación de este esquema doctrinal sólo se entiende dentro del marco constitucional de cada país, "según las relaciones entre los poderes del Estado, Legislativo y Ejecutivo, en el ejercicio de la función presupuestaria, precisando el justo sentido de la intervención del poder legislativo en la aprobación de los Presupuestos del Estado". El Presupuesto del Estado. Introducción al Derecho Presupuestario, Tecnos, Madrid 1970. pág. 53. Autores como Francisco EsCrIBANo LóPEz, reconociendo esto, mantienen sin embargo, que la polémica planteada acerca de la ley de presupuestos como una ley formal es un tema central que continúa siendo recurrente a la hora de tratar todas estas cuestiones, vid., "Reforma tributaria y aprobación de presupuestos. Análisis de una experiencia (1978-1981)" en Funciones financieras de las Cortes Generales, Congreso de los Diputados, Monografias 2, 1985, pág. 158. 
Una de las particularidades que llama la atención al estudiar la ordenación constitucional de la Ley de Presupuestos Generales del Estado hace referencia a la prohibición que impone el artículo 134.7 de la Norma Fundamental, esto es, la interdicción absoluta de que la ley de presupuestos cree tributos o los modifique sin la previsión de una ley tributaria sustantiva.

Considero de sumo interés descifrar el significado del término ley tributaria sustantiva que se opone a la ley de presupuestos, con el objeto de reforzar la idea expresada anteriormente acerca de la naturaleza de esta ley.

¿Acaso nuestra constitución reabre con esta terminología, viejas categorias que se entendian superadas? ¿Quizá la ley de presupuestos no es una ley sustantiva y sí lo son todas las demás?

La ambigüedad de la jurisprudencia constitucional en esta materia ha dado pie a que cualquier ley, salvo la de presupuestos, sea considerada apta para crear y modificar tributos ${ }^{18}$. Como ejemplo, la Ley de Medidas fiscales, administrativas y de orden social que acompaña cada año a la ley de presupuestos crea impuestos (en la ley del 96 el de Primas de Seguros y en la del 98 , el impuesto sobre la electricidad) y modifica sustancialmente algunos de los existentes (la ley del 99, reforma el IRPF, el IVA, la Ley de impuestos especiales y el impuesto de transmisiones $y$ actos jurídicos documentados, entre otros). Desde mi punto de vista una interpretación más restrictiva del término "ley tri-

18 En su Sentencia 27/1981, FJ. $3^{\circ}$, el Tribunal barajó distintas posibles interpretaciones del término ley tributaria sustantiva. Según una primera interpretación, por esta locución habría que entender uel precepto o conjunto de preceptos tributarios que están alojados en un cuerpo legal que no es la Ley de Presupuestos." En el extremo opuesto de esta interpretación estaría una segunda que entendería, por ley sustantiva tributaria, la ley propia de cada tributo. Entre ambas opciones el Constitucional opta por una via intermedia y entiende que "cuando el art. 134.7 habla de "ley tributaria sustantiva» se remite a cualquier Ley (propia del impuesto o modificadora de ésta) que, exceptuando la de Presupuestos, regule elementos concretos de la relación tributaria." Esta interpretación no obstante, no se expresa tan matizadamente en otras ocasiones, como en la STC 182/1997, donde el Tribunal parece más próximo a la primera de las interpretaciones que barajó en su dia: "...un examen sistemático del texto de la Constitución en lo que hace a las fuentes del sistema tributario, de cuyo conjunto trabado de limitaciones se deduce que no cualquier Ley (o norma con rango y fuerza de Ley) es apta para regular la materia tributaria, así: Ios límites a la utilización de Decreto-Ley (art. $86.1 \mathrm{CE}$ ); la exclusión de las leyes de iniciativa popular en materia tributaria (art. $87.3 \mathrm{CE}$ ) o la prohibición de crear o, en su caso, de modificar tributos por medio de la Ley de

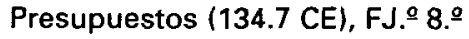


butaria sustantiva", evitaría, en primer lugar, que leyes como la de acompañamiento cuya tramitación de urgencia no es precisamente garantía de un estudio y debate serenos fueran consideradas apropiadas para la creación y modificación de tributos y en segundo término, despojaría de argumentos a quienes pretenden seguir manteniendo categorias trasnochadas.

No parece descabellado entender que, cuando la Constitución exige una ley sustantiva está exigiendo una ley propia, específica del impuesto, lo que por una parte supone equiparar la ley de presupuestos a otras leyes que no pueden regular esta materia y por otra, implica un mandato de promover la codificación en materia tributaria, concretando de este modo el principio de seguridad jurídica en un aspecto especialmente sensible para los ciudadanos.

A resultas de este planteamiento no podría considerarse conforme a la Constitución la utilización de cualquier ley para crear o modificar de forma sustantiva un tributo, como lo hacen, año tras año, las leyes de acompañamiento, cuya falta de idoneidad para regular estas materias deriva de un procedimiento que si bien formalmente no está afectado por las restricciones de los derechos de participación que soporta el iter legis presupuestario, de hecho, por desarrollarse en función de la ley de presupuestos, no garantiza un análisis detallado de materias que, por su importancia, merecerian un tratamiento parlamentario diferenciado.

Pero los problemas que aquejan a las leyes de medidas fiscales, administrativas $y$ de orden social son más extensos y profundos.

El recurso a las leyes de acompañamiento se produce como consecuencia de la Sentencia 76/1992 del Tribunal Constitucional ${ }^{19}$.

Hasta ese momento, la ley anual venía siendo utilizada como auténtica ley saco, ley omnibus a través de la que se regulaban materias que poco o nada tenían que ver con las previsiones de ingresos y gastos pero mucho con las necesidades coyunturales de modificar el ordenamiento del Gobierno de turno.

El Tribunal Constitucional manifestó en la Sentencia citada y en repetidas ocasiones posteriormente que las especialidades en el iter legis presupuestario y concretamente las restricciones al derecho de enmienda imponían una barrera al contenido posible de la ley de pre-

19 Con posterioridad, se repite esta línea jursiprudencial en resoluciones como las SSTC 178/1994 de 16 de junio o la 195/1994 de 28 de junio. 
supuestos que no podía abarcar cualquier asunto sino únicamente aquellos que guardaran relación directa suficiente con la cuenta de ingresos y la habilitación de gastos.

Como respuesta a esta jurisprudencia el Ejecutivo presenta cada año al Congreso, el Proyecto presupuestario acompañado de un Proyecto de Ley de Medidas Fiscales, Administrativas y de Orden Social que incluye una amalgama de contenidos, todos aquellos que anteriormente recogía la Ley de Presupuestos ${ }^{20}$.

A mi entender, esta técnica legislativa padece de un importante déficit democrático por menoscabar el derecho de enmienda y el de debate, puesto que la tramitación de este proyecto en paralelo al de presupuestos implica la reducción de los plazos de examen y enmienda, extendiéndose las limitaciones de las competencias del legislativo a materias que poco o nada tienen que ver con la política económica y agravándose, de este modo y por la vía de hecho, el fraude constitucional que el Alto Tribunal pretendió evitar con su jurisprudencia restrictiva del contenido de las leyes de presupuestos. Pero es que además lesiona gravemente el principio de seguridad juridica, porque parece excesivo imponer al ciudadano $y$ al aplicador del derecho la carga de indagar dónde se establece la regulación de las diversas materias, a causa de la falta de diligencia del legislador ${ }^{21}$.

Analizadas las cuestiones generales referidas a la ley de presupuestos y a su acompañante Ley de Medidas Fiscales, se hace necesario examinar la limitación contemplada en el artículo 134.6 de la Cons-

20 Sobre el contenido de estas leyes y los problemas que plantean puede consultarse la monografía de L.M. - Cazorla Prieto, Las llamadas leyes de acompañamiento presupuestario (sus problemas de constitucionalidad), IEF, Marcial Pons, Madrid 1998.

21 Es indudable que el Gobierno tiene la necesidad de acomodar la legislación a las previsiones presupuestarias de cada nuevo ejercicio y en este sentido una ley de medidas fiscales, administrativas y del orden social es un complemento necesario al servicio de la función de dirección politica del Gobierno. Los problemas surgen de la voluntad del Ejecutivo de introducir en este proyecto medidas no directamente necesarias para la aplicación de la ley pero que le son de utilidad para otros fines. La falta de restriccicones jurídicas a la tramitación de la ley de acompañamiento permite esta práctica. Sin embargo de hecho, las especialidades procedimentales de la ley de presupuestos se extienden a la tramitación de este provecto, que se presenta a la Cámara días despues del texto presupuestario y se aprueba el mismo día que la Ley de Presupuestos. El resultado es el mismo fraude constitucional, en este caso por vía de hecho, que pretendió evitar el Tribunal Constitucional con su Jurisprudencia restrictiva del contenido de las leyes de presupuestos. 
titución. Se trata de determinar, si el Texto Fundamental exige que toda enmienda presentada al Proyecto de ley de Presupuestos que suponga aumento de gastos o disminución de ingresos, únicamente pueda ser tramitada con la conformidad del Gobierno.

Tal cuestión no puede abordarse exclusivamente desde una interpretación histórica, comparada o literal del precepto, incapaz de aportar soluciones satisfactorias, sino principalmente, desde una exégesis sistemática y teleológica del texto apoyada en los valores y principios constitucionales y adaptada a la forma de gobierno parlamentaria.

En este orden de cosas no parece adecuada una interpretación a la luz de los Reglamentos parlamentarios, como estima conveniente algún autor ${ }^{22}$, sino todo lo contrario, porque es posible, y así lo entiendo, que las normas reglamentarias, en exceso restrictivas de la capacidad de enmienda, deban considerarse autolimitaciones parlamentarias que incluso no participan, en buena medida, del espíritu orientador de la Norma Fundamental concretado en el reconocimiento del principio democrático y del valor pluralismo político.

En este sentido las restricciones que incorpora el ordenamiento jurídico, han de interpretarse de forma favorable al derecho de enmienda, es decir, de manera tal que se permita la defensa y el debate de las distintas opciones políticas, con independencia de que la decisión la tome democráticamente la mayoría.

Esto significa, circunscribir el campo de aplicación de la limitación del derecho de enmienda a los proyectos de contenido económico que se tramitan con posterioridad a la aprobación de la ley de Presupuestos y, en consecuencia, no aplicar dichas limitaciones al debate de la ley anual.

En efecto, este debate de la ley de presupuestos, de gran trascendencia política, ha de ser lo más abierto posible sin que sea necesario que concurra la conformidad del Ejecutivo para la admisión a trámite de aquellas enmiendas que supongan un aumento de créditos o una minoración de ingresos.

Tal conclusión no se contradice con la dinámica del parlamentarismo racionalizado, pues de lo que se trata no es de oponer la gober-

22 Por ejemplo, C.A. Garcia-Quintana, comentando la Ley de Presupuestos del Estado señala que, "se juzga prudente interpretar el artículo 134.6 de la Constitución, según lo han hecho los Reglamentos del Congreso de Diputados y del Senado...". Vid., Comentario al artículo 134 de la Constitución, en Comentarios a las Leyes Políticas, T. X, dirigidos por O. AlzaGa VILLAMIL, Edersa, Madrid 1985, pág. 293. 
nabilidad al juego de los principios pluralista y democrático, sino de encontrar el equilibrio y la ponderación de todos los elementos que conviven en el texto constitucional.

En este caso concreto, se trata de conciliar el ejercicio de la función de gobernar con la no menos necesaria función de controlar al que gobierna que es propia de las Cortes Generales.

No obstante, los Reglamentos optan por la limitación de las facultades y derechos de los representantes en el desarrollo del procedimiento presupuestario y de este modo exigen la autorización del Ejecutivo para tramitar cualquier propuesta que pueda implicar desviaciones presupuestarias. En la práctica, dicha regulación plantea serios inconvenientes y una carga excesiva para el Ejecutivo que generalmente asume de manera muy relajada.

Por todo ello, lege ferenda, sería conveniente que los Reglamentos circunscribiesen este requisito a la tramitación de las proposiciones y enmiendas que pudieran poner en peligro el presupuesto ya aprobado, $y$ estableciesen, por otra parte, fórmulas como la de compensación que permiten a los parlamentarios ofrecer opciones políticas y económicas alternativas sin que tales propuestas impliquen necesariamente desajustes presupuestarios.

\section{EL DERECHO DE ENMIENDA COMO MANIFESTACIÓN DE LOS DERECHOS EN LA REPRESENTACIÓN DEL ARTÍCULO 23 DE LA CONSTITUCIÓN}

Para finalizar este breve recorrido por algunos de los problemas que atañen al derecho de enmienda se hace preciso observar esta institución parlamentaria desde la perspectiva del derecho de enmienda como derecho de participación de los representantes en las funciones de las Cortes Generales.

Como es sabido, el artículo 23 de la Constitución española reconoce los derechos de los ciudadanos a participar directamente o por medio de representantes en los asuntos públicos. Este primer párrafo se complementa con una segunda norma en la que se reconoce el derecho a acceder en condiciones de igualdad a las funciones $y$ cargos públicos con los requisitos que señalen las leyes.

En reiterada jurisprudencia, llena de matices y no exenta de reproches, el Tribunal Constitucional ha interpretado que el contenido del derecho constitucionalizado en el artículo 23.2 no se limita al acce- 
so a los cargos públicos en condiciones de igualdad sino que abarca además, el derecho a permanecer en los mismos sin perturbaciones ilegítimas (STC 60/1982 y 5/1983).

Por otra parte, y con relación a los cargos públicos representativos, conocida es la jurisprudencia del Tribunal que interpreta conjuntamente los dos apartados del artículo 23, entendiendo que el sufragio activo y pasivo son aspectos indisociables de una misma institución: la representación, nervio y sustento de la democracia (STC 24/1990) ${ }^{23}$.

La exégesis conjunta de los dos apartados de dicho precepto, unida a la especial ubicación de la norma, dentro de la Sección 1. $\stackrel{a}{\text { a }}$ del Capítulo 2.o, permite comprender desde otra óptica el Derecho parlamentario y abre nuevas posibilidades para la defensa de los derechos de las minorías.

La doctrina mayoritariamente reconoce que el complejo status jurídico del parlamentario incorpora derechos constitucionalizados como fundamentales, cuya protección corresponde no sólo a los órganos de las Cámaras sino también al Tribunal Constitucional como máximo garante de los derechos fundamentales que $\mathrm{es}^{24}$. No obstante hay

23 El Tribunal ha mantendio desde muy temprana jurisprudencia que el derecho de participación de los ciudadanos en la vida pública y el derecho a ejercer la representación por parte del cargo público representativo, sin perturbaciones ilegitimas, se encuentran intimamente relacionados. Por consiguiente, el derecho de sufragio y el derecho a la representación son las dos caras de una misma moneda, cfr., entre otras, SSTC 10/1983, 75/1985, 181/1989, 205/1990 -y Jurisprudencia contenida en esta última decisión, o 124/1995-.

24 Sin pretender ser exhaustivos, respaldan esta tesis con sus trabajos: E. Cobreros Mendazona, "El status parlamentario como derecho fundamental», en Estudios sobre la Constitución española. Homenaje al Profesor E. Garcia de Enterria, vol. III, Cívitas, Madrid 1991, págs. 2157 y ss. De este mismo autor y A. SAIZ ARnalz, "La defensa del Status del Parlamentario", op. cit., págs. 109 y ss.; J. Ballarín IribaRREN, "El derecho de acceso a los cargos y funciones públicas», en Poder Judicial, n. 5, 1987, págs. 124 y ss.; I. Torres Muro, "Actos internos de las Cámaras y recurso de amparo. Un comentario al Auto del Tribunal Constitucional de 21-111-84", REDC, n. 12, 1984; J.M. Morales Arroyo y M. Revenga Sánchez, "Un apunte sobre jurispudencia constitucional y derecho parlamentarion, en $R C G, n .27,1986$, págs. 181 y ss. A. Torres del Moral, Principios de Derecho Constitucional español, vol II, Atomo, Madrid, 1986, págs. 107 y ss.; E. Mancisidor ArTaraz, "El derecho de los parlamentarios a recabar información (comentario a la STC 161/1988 de 20 de septiembre) en RVAP, n. 24, 1989, págs. 204 y ss.; J. C. DA SILVA OCHOA, "El derecho de los parlamentarios a la documentación", en RCG, n.19, 1990, págs. 37 y ss. J. Cano Bueso, El derecho de acceso a la documentación de los Diputados en el ordenamiento parlamentario español, Ed. del Congreso de los Diputados, Madrid 1996, págs. 50 y ss.; J. GaRcía RocA, Cargos Públicos Representativos. Un estudio del ar- 
que señalar, en primer lugar que, dentro de dicho status constitucional, se agrupan derechos heterogéneos. Con el objeto de sistematizar y en definitiva, comprender mejor el alcance de dichos derechos se propone diferenciar lo que son derechos de los parlamentarios presupuesto para el ejercicio de la función representativa de lo que son derechos en la representación.

Entre los primeros, configuran el status individual del parlamentario la inviolabilidad, la inmunidad, la retribución y el derecho al mandato.

Tales derechos, con independencia de su dimensión objetiva o institucional gozan, según creo, de una dimensión subjetiva e individual.

En efecto, estos derechos se configuran al servicio de garantizar la formación de una Cámara independiente y libre, así como de asegurar la igualdad de oportunidades en el acceso y ejercicio del cargo lo que, en definitiva, se traduce en la garantía de una representación política plural, libre e independiente. Pero lo cierto es que al mismo tiempo, estas instituciones hacen nacer una pretensión individual susceptible de tutela jurisdiccional, que puede denominarse derecho subjetivo, derecho reflejo o interés jurídicamente protegido.

En la medida en que esta clase de derechos configuran el status jurídico individual de los miembros de la Cámara considero que son derechos-presupuesto para el ejercicio de la función representativa y reclaman necesariamente una regulación desde la estricta aplicación del principio de igualdad.

Por el contrario, el resto de derechos que constituyen la actuación de las competencias derivadas de la función representativa admiten perfectamente, aunque hasta cierto punto, un ejercicio de carácter desigual en función de criterios de organización interna de la Cámara pero sobre todo de la pertenencia a un grupo parlamentario.

A este conjunto de derechos los he denominado derechos en la representación, y son aquellos derechos-instrumento del pluralismo político que sirven al parlamentario en el desempeño de las funciones

tículo 23.2 de la Constitución, Aranzadi, Pamplona 1999.Mantienen una opinión contraria a esta, P. BIGLINO CAMPOS, "Las facultades de los parlamenterios ison derechos fundamentales, en RCG, n. 30,1993 y J. Jiménez CAMpo, "Sobre los derechos fundamentales de los parlamentarios", en la obra colectiva Parlamento y Justicia constitucional. IV Jornadas de la Asociación Española de Letrados de Parlamentos, coordinada por F. PAU VALL, Aranzadi, Pamplona 1997. 
concretas que las Cámaras tienen encomendadas constitucionalmente. Entre ellos el derecho de propuesta, el derecho de enmienda, el derecho a participar en los órganos de trabajo de la Asamblea, a ejercer la función de control, el derecho de voto, así como el derecho a ser elector $y$ elegible en las elecciones a cargos representativos de la Cámara.

Los derechos en la representación los disfruta plenamente el parlamentario como miembro del grupo ideológico al que pertenece, siendo relevante su adscripción política y obrando aquí el principio de representación proporcional como factor para detectar posibles lesiones de dichos derechos.

Bajo esta perspectiva, el principio de igualdad no opera aquí del mismo modo que lo hace en los derechos-presupuesto, donde se aplica como principio de equivalencia, sino que para constatar un eventual menoscabo de los derechos en la representación, el Tribunal habrá de realizar un juicio de proporcionalidad, teniendo en cuenta la adscripción política del parlamentario y la carga de representación del grupo al que pertenece.

Aplicando esta argumentación al derecho de presentar y defender enmiendas, la primera conclusión que se extrae es que tal derecho de los sujetos parlamentarios forma parte integrante del contenido esencial del ius in officium, puesto que se trata de un instrumento útil y necesario para ejercer la función representativa en los procedimientos legislativos y de control.

En este sentido, le son aplicables las características anteriormente indicadas, esto es, su pleno disfrute se obtiene a través del Grupo y es el representante como miembro del grupo, quien ejerce el derecho de enmienda en toda su extensión.

Dicho esto, no puede sin embargo olvidarse que el derecho de enmienda forma parte del ius in officium del parlamentario to que implica que, en alguna medida $y$ aunque sea de forma residual, ha de poder permitirse su ejercicio individual. De ahi que haya de entenderse la exigencia reglamentaria de la firma del Portavoz del Grupo Parlamentario, no como una conditio sine qua non para la presentación de enmiendas sino como una mera exigencia de dar a conocer, comunicar, notificar o informar al grupo del contenido de la enmienda.

Por lo tanto, en el supuesto de que el Portavoz se niegue a rubricar el escrito, por discrepancias con el titular de la enmienda, entiendo que ha de ser la Mesa de la Comisión o en su caso la de la Cámara, el órgano que compruebe que el Portavoz ha sido informado y tiene 
conocimiento de la existencia y contenido del escrito, en cuyo caso habrá de admitir a trámite el documento. De lo contrario, no sólo se estará produciendo una infracción del Reglamento sino que se estará imponiendo jurídicamente, a través de una interpretación incorrecta del precepto, la disciplina de partido al parlamentario, a la vez y más importante que contraviniendo el mandato constitucional recogido en el artículo 67.2 en relación con el artículo 23.2 de la Constitución.

En otro orden de cosas, como ha reiterado el Tribunal Constitucional, el derecho de enmienda encuentra acomodo entre los llamados derechos de configuración legal ${ }^{25}$, determinando su régimen normativo, el propio texto constitucional (arts. 84 y $134.6 \mathrm{CE}$ ) y especialmente los Reglamentos parlamentarios.

Dicho esto, no puede desconocerse, sin embargo, la existencia de un contenido mínimo, indisponible, que deriva del reconocimiento de que se trata de una facultad esencial incardinada en el status del parlamentario, necesaria para la actuación de la representación y, en definitiva de los principios democrático y pluralista en las funciones que las Cortes tienen encomendadas ex Costitutione.

De esta afirmación se deriva que el legislador no podrá suprimir el derecho, ni limitarlo hasta el punto de hacerlo irreconocible.

En este orden de cosas, algunos procedimientos reglamentariamente previstos como el de lectura única y utilizaciones abusivas de procedimientos como el de urgencia suponen, desde esta perspectiva, un menoscabo del derecho de enmienda $y$, en consecuencia, de los derechos de participación que son exigencia del principio democrático y pluralista.

Y mantengo este criterio a pesar de algunas resoluciones del Tribunal Constitucional, como la reciente Sentencia 27/2000 de 31 de enero, en la que el Alto Tribunal desestima un recurso de amparo interpuesto por varios representantes en el Parlamento Vasco contra el Acuerdo de la Mesa que, impone el procedimiento de lectura única a la tramitación de un proyecto sobre las aportaciones económicas de las Diputaciones Forales a los presupuestos de la Comunidad Autónoma.

Dicho procedimiento significa, como se sabe, que en el iter legis no cabe la tramitación de enmiendas de ninguna clase, lo que supone

${ }^{25}$ Acerca de las características de los derechos de configuración legal, vid. por todos, J.L. Requejo PAGÉs, voz "Derechos de configuración legal" en Enciclopedia Jurídica Cívitas, vol II, Madrid 1994, págs. 2385 y ss. 
que la Cámara se limita bien a aprobar el texto, bien a rechazarlo en su totalidad.

En mi opinión sería conveniente revisar la naturaleza jurídica de las leyes pactadas que llegan cerradas al Parlamento, porque puede ser que no se trate de auténticas leyes sino de acuerdos extra parlamentarios, que requieren una ratificación de la Cámara como si de una autorización se tratara, pero cuya tramitación, se aleja de lo que constituye la esencia del procedimiento legislativo.

$Y$ es que si algo diferencia la ley del resto de normas del ordenamiento es precisamente su procedimiento agravado de elaboración en el que participan o al menos tienen que poder participar los representantes de las distintas opciones, a través de instrumentos como la enmienda que canalizan el pluralismo político en sede parlamentaria. 